\title{
Evaluation of Genetic Diversity in Korean Fir Cultivars Based on Microsatellite and Cytoplasmic Markers
}

\author{
Myounghai Kwak, Jeong-Ki Hong, Eun Sil Lee, Byoung Yoon Lee, and Min Hwan Suh \\ National Institute of Biological Resources, Incheon 22689, South Korea \\ Bert Cregg \\ Michigan State University, Department of Horticulture and Department of Forestry, East Lansing, MI \\ 48824
}

\begin{abstract}
AdDITIONAL INDEX wORDS. artificial selection, inbreeding coefficient, linkage disequilibrium, NAD5 intron3, population structure, trnL-F intergenic spacer

Abstract. Korean fir (Abies koreana) has been cultivated for less than 100 years, mainly in the United States and Europe. Using nuclear microsatellite, mitochondrial, and chloroplast markers, we investigated the origin of cultivated korean fir from South Korea (KC group) as well as the United States and United Kingdom (EU group), and compared these samples to published data from wild populations. All genotypes in the EU and KC groups were most closely related to the wild individuals from Mt. Hallasan, the southernmost $A$. koreana population on Jejudo Island (South Korea). However, the presence of the chloroplast haplotypes clustered with Abies balsamea in two EU cultivars and the higher diversity values of the $E U$ group compared with the wild individuals from Mt. Hallasan infer a certain level of introgression from different species during cultivation. The EU group had a higher inbreeding coefficient and linkage disequilibrium, and a smaller proportion of rare alleles, than the wild populations. This suggests that the genetic characteristics of korean fir cultivars reflect strong artificial selection pressure for desirable horticultural traits and asexual reproduction. Last, this genetic background study suggests that the other wild populations in the Korean peninsula can serve as valuable genetic resources for future breeding.
\end{abstract}

Korean fir (A. koreana) is a popular ornamental conifer planted in cold-climate gardens and preferred as Christmas trees in North American and European countries (Cregg, 2008). This species is endemic to Korea, where it is currently distributed in the southern part of the Korean peninsula and on Jejudo Island, South Korea (Kwak et al., 2017) (Fig. 1). Although natural $A$. koreana forests are found only at high elevations on two mountains (Mt. Jirisan on the Korean Peninsula and Mt. Hallasan on Jejudo Island), small patches or groups of a few individuals are distributed only around the tops of a few mountains on the Korean peninsula. The International Union for Conservation of Nature has designated this species to be critically endangered in response to its continuous decline and fragmented populations.

A wide range of korean fir cultivars are available. As of June 2019, the American Conifer Society recognized 42 cultivars of $A$. koreana. This large number of cultivars was likely generated by the intense selection of mutations (Auders and Spicer, 2012). Interestingly, the dissemination of $A$. koreana from its country of origin was started by two French priests, Urban Faurie and Emile Joseph Taquet, who collected $A$. koreana for herbarium vouchers from Mt. Hallasan in 1907 (Kim et al., 2007). These vouchers were distributed to several renowned herbaria in Europe and the United States in the early 20th century (Kim et al., 2007) and $A$. koreana was described as a new species in 1920 (Wilson, 1920).

Received for publication 27 June 2019. Accepted for publication 10 Oct. 2019. Published online 25 November 2019.

Current address of J.K.H. and M.H.S.: Nakdonggang National Institute of Biological Resources, Sangju 37242, South Korea

M.K. is the corresponding author. E-mail: mhkwak1@korea.kr.

This is an open access article distributed under the CC BY-NC-ND license (https://creativecommons.org/licenses/by-nc-nd/4.0/).
A tree generated from the seed of the type specimen (E.H. Wilson, collection no. 9486) still grows at the Arnold Arboretum in Boston, MA (Kim et al., 2007). Following the initial dissemination of the specimens and seeds among botanical institutions and nurseries, cultivars were selected between the 1960s and 2000s, mainly in the United States, Germany, The Netherlands, and United Kingdom (Auders and Spicer, 2012).

The genetic evaluation of horticultural germplasm is an important step in planning optimal management strategies, characterizing collections, selecting core subsets, and promoting further genetic enhancement of cultivars (Bretting and Widrlechner, 1995; Mohammadi and Prasanna, 2003). Investigating genetic relationships between cultivated and wild germplasm also provides useful insight for breeding programs (Cornille et al., 2012; Dempewolf et al., 2017; Migicovsky and Myles, 2017; Moran and Bell, 1987). For example, a population genetics study of cultivated and wild apricot (Prunus armeniaca) using microsatellite markers suggested that apricots were first cultivated in central Asia and China, and revealed a high proportion of accessions resistant to Plum pox virus in these areas (Decroocq et al., 2016). Analysis of genetic variation has also been applied to determine whether breeding for white pine blister rust (Cronartium ribicola) has affected diversity in western white pine (Pinus monticola) (Kim et al., 2003).

A previous microsatellite analysis of wild $A$. koreana populations showed that the species was structured into two genetic clusters: a single population on Mt. Hallasan (HL) on Jejudo Island and the Korean peninsula (KP) groups, including Mt. Deokyoosan (DY), Mt. Gayasan (GY), Mt. Jirisan (JR), Mt. Sinbulsan (SB), and Mt. Sokrisan (SR) (Fig. 1) (Kwak et al., 2017). The genetic diversity of the HL cluster is the lowest 


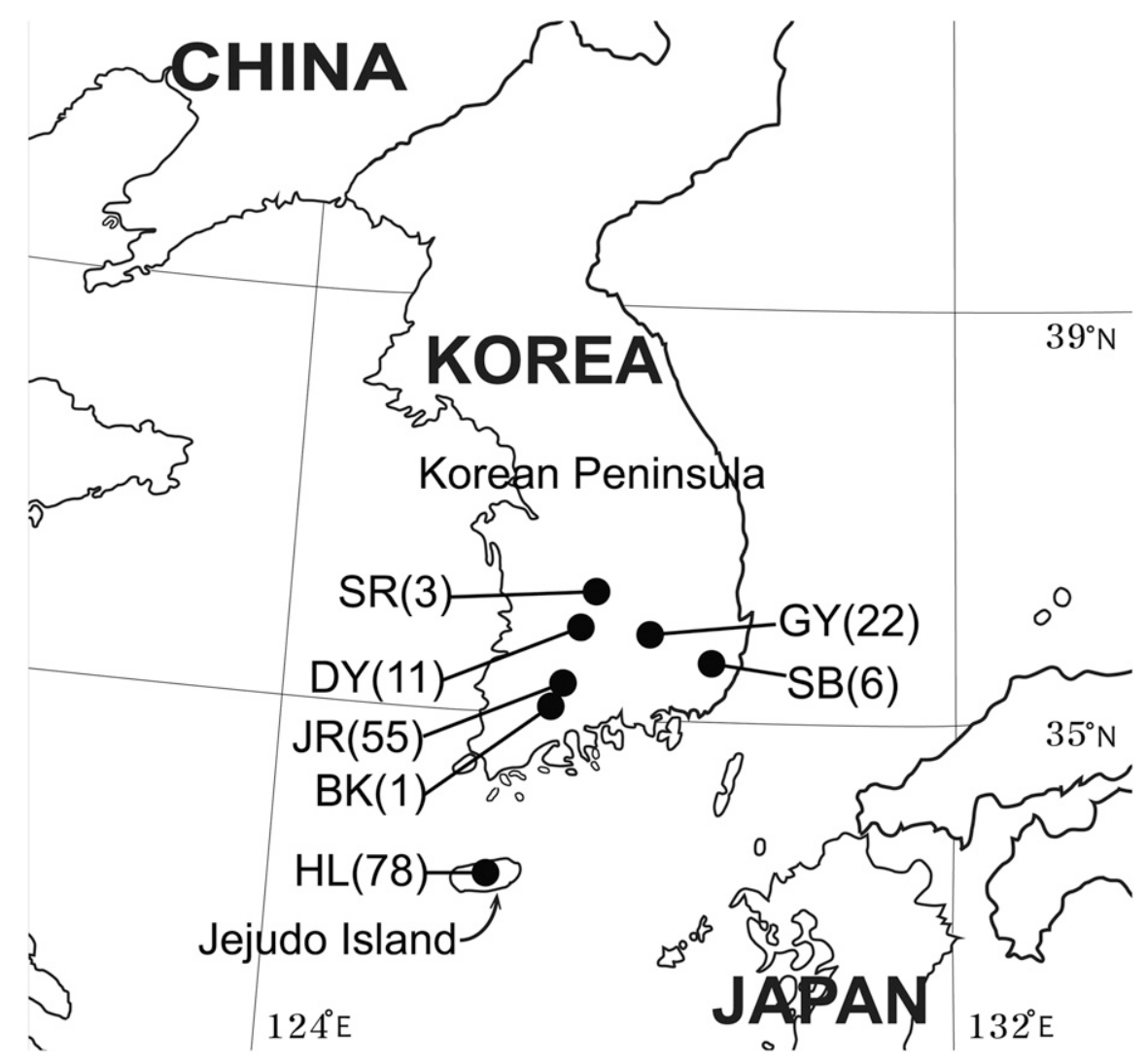

Fig. 1. Geographic distribution of wild populations of korean fir included in this study. The acronyms designating wild populations are as follows: BK= Mt. Baekwoonsan; DY $=$ Mt. Deokyoosan; GY = Mt. Gayasan; HL = Mt. Hallasan; JR = Mt. Jirisan; SB = Mt. Sinbulsan; SR = Mt. Sokrisan. BK, DY, GY, JR, SB, and SR are the wild populations in the Korean peninsula and $\mathrm{HL}$ is the southmost wild population in Jejudo Island. The numbers in parentheses indicate the number of individuals included.

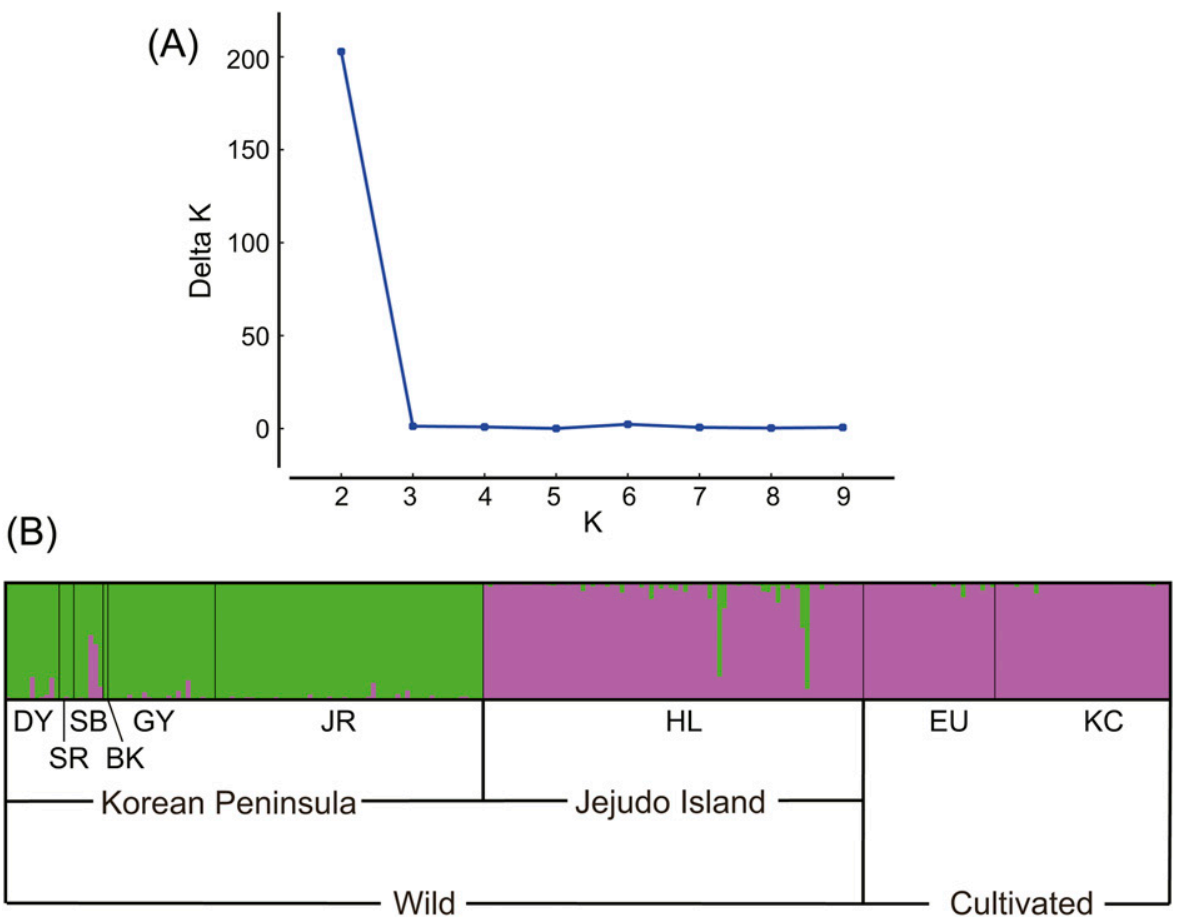

Fig. 2. Graphical presentation of the results of a STRUCTURE version 2.3.4 analysis (Pritchard et al., 2000) of korean fir. (A) Graph of delta K values to rate of change in the log probability between K. (B) STRUCTURE bar plot for optimal two clusters $(K=2)$. Colors indicate the percentage contribution of individuals to the assigned clusters ( $y$-axis). Green indicates the Korean peninsula cluster (KP), and pink indicates the Mt. Hallasan cluster (HL). Each line represents an individual ( $x$-axis). Codes for wild and cultivated populations: $\mathrm{BK}=\mathrm{Mt}$. Baekwoonsan; DY = Mt. Deokyoosan; GY = Mt. Gayasan; $\mathrm{EU}=$ cultivated in the United States and United Kingdom; HL = Mt. Hallasan; JR = Mt. Jirisan; KC = cultivated in South Korea; SB = Mt. Sinbulsan; SR = Mt. Sokrisan. BK, DY, GY, JR, SB and SR are the wild populations in the Korean peninsula and HL is the southmost wild population in Jejudo Island. 
Table 1. Commercial korean fir cultivars genotyped with microsatellite and cytoplasmic markers in the present study.

\begin{tabular}{|c|c|c|}
\hline$\overline{\text { Group }^{z}}$ & Cultivar & Provider $^{y}$ \\
\hline \multirow[t]{27}{*}{$\overline{\mathrm{EU}}$} & Aurea & KG \\
\hline & Blauer Pfiff & KG \\
\hline & Blue and Silver & $\mathrm{LC}$ \\
\hline & Blue Magic & $\mathrm{LC}$ \\
\hline & Cis & KG \\
\hline & Compact Dwarf & KG \\
\hline & Dark Hill & $\mathrm{LC}$ \\
\hline & Dwarf Prostrata & WS \\
\hline & Fliegender Untertasse & KG \\
\hline & Frosty & $\mathrm{KG}$ \\
\hline & Gait & DF \\
\hline & Gelbbunt & JME \\
\hline & Glauca & KG \\
\hline & Goldener Traum & JME \\
\hline & Inge & $\mathrm{LC}$ \\
\hline & Kleiner Prinz & $\mathrm{LC}$ \\
\hline & Kohouts Icebreaker & DF \\
\hline & Kristalkugel & $\mathrm{LC}$ \\
\hline & Laminetta & WS \\
\hline & Oberon & DF \\
\hline & Ry & $\mathrm{LC}$ \\
\hline & Schneestern & $\mathrm{LC}$ \\
\hline & Silberkugel & $\mathrm{LC}$ \\
\hline & Silberlocke & JME \\
\hline & Silberperle & $\mathrm{LC}$ \\
\hline & Silberschmeltzer & $\mathrm{LC}$ \\
\hline & Silver Show & JME \\
\hline \multirow[t]{5}{*}{$\mathrm{KC}$} & $\mathrm{n}=11^{\mathrm{x}}$ & DL \\
\hline & $\mathrm{n}=5^{\mathrm{x}}$ & GS \\
\hline & $\mathrm{n}=5^{\mathrm{x}}$ & NM \\
\hline & $\mathrm{n}=10^{\mathrm{x}}$ & KI \\
\hline & $\mathrm{n}=5^{\mathrm{x}}$ & $\mathrm{JA}$ \\
\hline
\end{tabular}

${ }^{\mathrm{z}} \mathrm{EU}=$ cultivars in the United States and United Kingdom; $\mathrm{KC}=$ cultivated in South Korea.

${ }^{\mathrm{y}} \mathrm{DF}=$ Dragon Farms Nursery, Trenton, NJ; DL = Daelim Nursery, Gacheon, South Korea; GS = Gasan Farm, Seoul, South Korea; JA = Jungang Nursery, Seongnam, South Korea; JME = Japanese Maples and Evergreens, Vancouver, WA; KG = Kigi Nursery, Kelso, WA; $\mathrm{KI}=$ Kangil Farms, Okchoen, South Korea; LC = Larch Cottage Nurseries, Penrith, UK; NM = Namuin Nursey, Uiwang, South Korea; WS $=$ RHS Garden Wisley, Woking, UK.

${ }^{\mathrm{x}}$ Because cultivated Abies koreana is sold in Korea without cultivar designations, cultivar names are not indicated for the Korean providers. We have indicated the number of seedlings obtained from each Korean provider.

among wild $A$. koreana populations. Based on the known dissemination of $A$. koreana from Korea to the United States through the Arnold Arboretum, we hypothesized that American and European cultivars originated from a small number of founder individuals from Mt. Hallasan. Therefore, we investigated the genetic diversity of $A$. koreana cultivars currently traded in the United States and Europe as well as cultivated seedlings traded within Korea. We then compared the genetic characteristics of these cultivars with previous results from wild populations using established microsatellite markers and cytoplasmic chloroplast and mitochondrial markers, with the aim of identifying the origin of cultivated plants and assessing genetic diversity through selection for cultivation.
Table 2. Shared allele distance $\left(\mathrm{D}_{\mathrm{SA}}\right)$ of wild and cultivated korean fir populations calculated based on microsatellite genotypes.

\begin{tabular}{lcccccccc}
\hline & BK $^{z}$ & DY & SB & SR & GY & JR & HL & EU \\
\hline DY $^{z}$ & 0.7525 & & & & & & & \\
SB & 0.7870 & 0.5498 & & & & & & \\
SR & 0.7500 & 0.5173 & 0.5789 & & & & & \\
GY & 0.7374 & 0.3472 & 0.5399 & 0.4980 & & & & \\
JR & 0.7110 & 0.3171 & 0.5353 & 0.5033 & 0.2847 & & & \\
HL & 0.7214 & 0.3765 & 0.5338 & 0.5493 & 0.3553 & 0.3149 & & \\
EU & 0.7591 & 0.4916 & 0.5483 & 0.6120 & 0.4879 & 0.4624 & 0.3095 & \\
KC & 0.7606 & 0.4706 & 0.5435 & 0.6134 & 0.4540 & 0.4263 & 0.2539 & 0.2982
\end{tabular}

${ }_{\mathrm{z}} \mathrm{BK}=$ Mt. Baekwoonsan; DY = Mt. Deokyoosan; GY = Mt. Gayasan; $\mathrm{HL}=$ Mt. Hallasan; JR = Mt. Jirisan; $\mathrm{SB}=$ Mt. Sinbulsan; $\mathrm{SR}=$ Mt. Sokrisan; EU = cultivars in the United States and United Kingdom; $\mathrm{KC}=$ cultivated in South Korea; BK, DY, GY, JR, SB, and SR are the wild populations in the Korean peninsula and HL is the southmost wild population in Jejudo Island.

\section{Materials and Methods}

We analyzed 27 commercial $A$. koreana cultivars from four providers in the United States and two providers in the United Kingdom (EU), and a total of 36 cultivated seedlings from five providers in Korea (KC) (Table 1). Young leaves were collected from the plants, dried in silica gel, and stored at $-80{ }^{\circ} \mathrm{C}$ until use. The dried leaves were ground in a bead mill (Tissue Lyser II; Qiagen, Hilden, Germany) and total genomic DNA was extracted using a DNeasy Plant Mini Kit (Qiagen). We amplified 19 microsatellite loci from specimens as described previously for wild A. koreana populations (Kwak et al., 2017). Two to four microsatellite primer pairs were amplified in each multiplex reaction using the Qiagen Multiplex polymerase chain reaction (PCR) Kit, according to the manufacturer's instructions. The PCR products were analyzed on a sequencer (ABI 3730 DNA analyzer; Applied Biosystems, Waltham, MA) using the Genescan 500 LIZ size standard (Applied Biosystems). Using GeneMarker 1.85 (Gene Codes Corp., Ann Arbor, MI), the amplified fragments from this study and previously published genotype data of 176 wild $A$. koreana individuals from HL and KP (Fig. 1) were visualized together and the size of each fragment was confirmed.

Population genetic diversity measures were calculated using GenAlEx version 6.4.1 (Peakall and Smouse, 2006) and compared with the results of wild populations (Kwak et al., 2017). Allelic richness was calculated assuming a sample size of 20 individuals using a rarefaction approach in ADZE (Szpiech et al., 2008). To investigate the genetic characteristics of $A$. koreana cultivars, further analysis was performed on the combined data from a total of 239 individuals, including the wild $A$. koreana described previously (Kwak et al., 2017). The shared allele distance $\left[\mathrm{D}_{\mathrm{SA}}\right.$ (Chakraborty and Jin, 1993)] was calculated using PowerMarker version 3.0 (Liu and Muse, 2005). A principal coordinates analysis (PCoA) was performed based on covariance matrices with data standardization using GenAlEx.

We used a model-based clustering procedure using Bayesian inference to assign multiple-locus genotypes to a predefined number of clusters (K) with STRUCTURE version 2.3.4 (Pritchard et al., 2000). To determine the ancestry of EU and $\mathrm{KC}$, the program was run 10 times for each $\mathrm{K}=1-10$ with a burn-in period of 100,000 and 100,000 subsequent iterations 


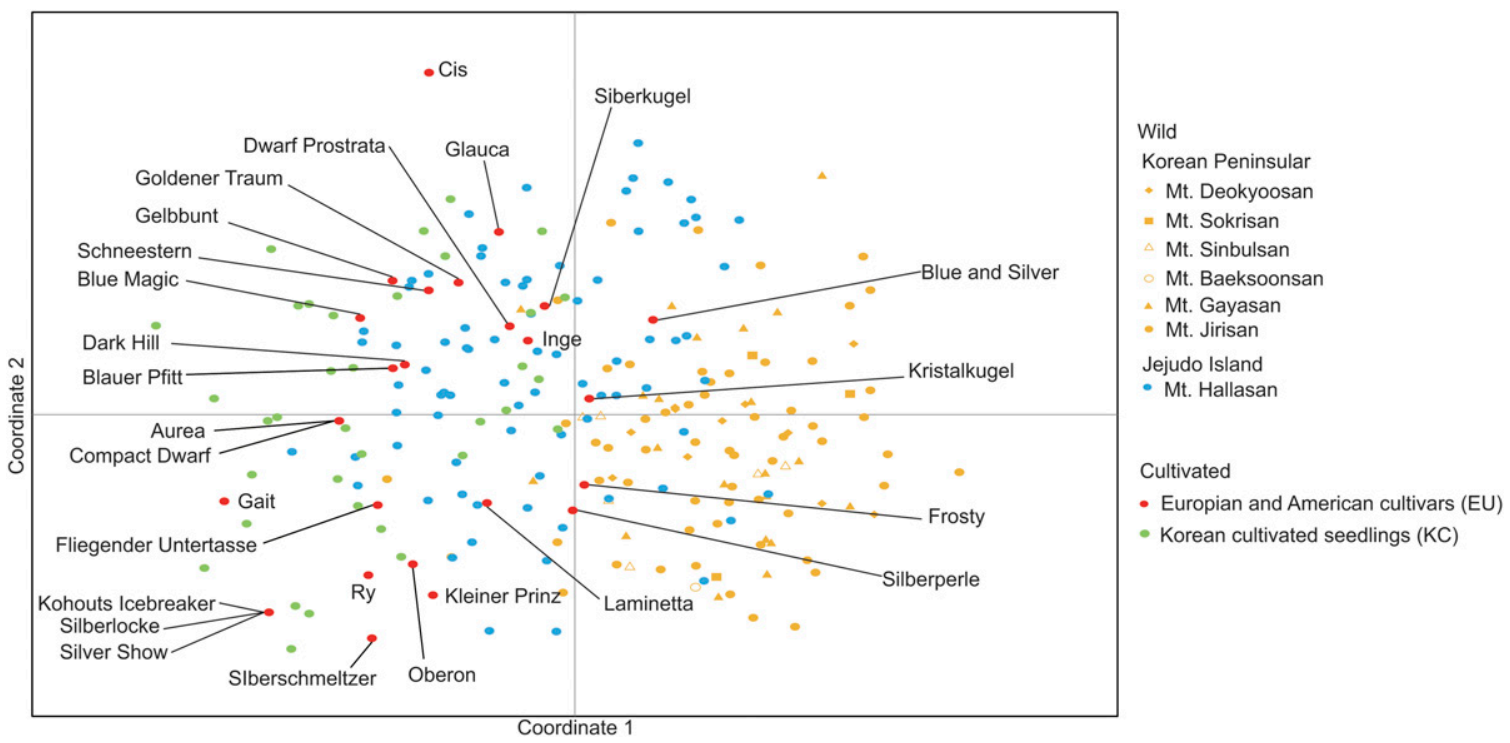

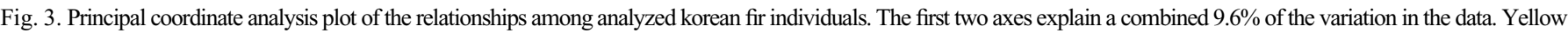
symbols indicate the wild individuals from the Korean peninsula (KP). Blue circles indicate the wild individuals from Mt. Hallasan on Jejudo Island (HL). Red circles indicate the cultivars from the United States and United Kingdom (EU). Green circles indicate the seedlings from the Korean peninsula (KC). The names of the EU cultivars are shown.

without prior information on the population of origin, in accordance with previously identified genetic clusters. The optimum number of clusters was determined using $\Delta \mathrm{K}$ (Evanno et al., 2005), implemented in the STRUCTURE HARVESTER program (Earl and von Holdt, 2012). CLUMPP version 1.1.2 (Jakobsson and Rosenberg, 2007) was used to obtain the average permuted individual and population Q matrices for 10 replicates. The matrices were then used as input for DISTRUCT version 1.1 (Rosenberg, 2004) to obtain bar plots in which each individual is represented as a segment divided into colors representing the estimated membership coefficients from each cluster.

Linkage disequilibrium (LD) between all pairs of loci was calculated using Arlequin version 3.5.1.3 (Excoffier et al., 2005). Because the haplotypic phase was unknown, the haplotype frequency was calculated as the product of the allele frequencies from the 19 microsatellites by an expectationmaximization algorithm with 1000 permutations. Pairwise LD among microsatellite marker pairs was tested using a likelihood-ratio test between the likelihood of the data obtained by estimated haplotype frequencies, assuming linkage equilibrium and the likelihood of the data assuming LD (Excoffier and Slatkin, 1998; Excoffier et al., 2005).

In Pinaceae, the mitochondrial genome is inherited maternally and that of the chloroplast paternally (Neale and Sederoff, 1989). Taking advantage of this unique cytoplasmic inheritance pattern, the mitochondrial NAD5 intron3 and chloroplast trnL$\mathrm{F}$ intergenic spacer regions were sequenced from most cultivars of the EU group, three to 10 individuals of the $\mathrm{KC}$ group, and one to four individuals of each wild population. 'Ry' and 'Silver Show' were not included, as genomic DNA was not available. Amplification was performed in a $10 \mu \mathrm{L}$ reaction containing $\approx 1$ ng of genomic DNA and 10 pmol of each primer using HYQ PCR premix (SNC, Seoul, South Korea), according to the manufacturer's instructions. The ND5 intron3 region was amplified using a forward primer (5'-CATCCCTCCCATTGCATTAT-3') and reverse primer [5'-GGACAATGACGATCCGAGATA-3' (Liepelt et al., 2002)], whereas the trnL-F intergenic spacer region was amplified using trnF
(5' ${ }^{\prime}$-ATTTGAACTGGTGACACGAG- $\left.{ }^{\prime}\right)$ and trnT [5'-CATTACAAATGCGATGCTCT-3' (Taberlet et al., 1991)]. Amplification consisted of $94{ }^{\circ} \mathrm{C}$ for $4 \mathrm{~min} ; 30$ cycles at $94{ }^{\circ} \mathrm{C}$ for 1 min, $55{ }^{\circ} \mathrm{C}$ for $1 \mathrm{~min}$, and $72{ }^{\circ} \mathrm{C}$ for 1 to $2 \mathrm{~min}$; and a final extension for $7 \mathrm{~min}$ at $72^{\circ} \mathrm{C}$. The PCR products were checked using QIAEXCEL (Qiagen). After purification using the Qiagen purification kit, the obtained fragments were sequenced in both directions on a 3730 DNA Sequencer at Macrogen (Seoul, South Korea). The chromatograms and alignments were checked visually and verified using Sequencer 5.0 (Gene Codes Corp.). The sequences generated in this study were deposited in the National Center for Biotechnology Information (NCBI) GenBank database under accession numbers MN445373 to MN445521. Alignments with the sequences of the trnL-F regions of other Abies species downloaded from NCBI GenBank were performed using ClustalW (Thompson et al., 1994). A neighbor-joining tree was constructed using the Tamura-Nei model without an outgroup using Genious 7.9.1 software (Biomatters, Auckland, New Zealand).

\section{Results and Discussion}

The optimum number of clusters for STRUCTURE analysis was $\mathrm{K}=2$ (Fig. 2). All individuals from the $\mathrm{EU}$ and $\mathrm{KC}$ groups were assigned to the same population as $\mathrm{HL}$ at $\mathrm{K}=2$. Similarly, $\mathrm{PCoA}$ showed that most individuals from the $\mathrm{EU}$ and $\mathrm{KC}$ were closer to the HL population than to the other wild populations (KP) (Fig. 3), and the $\mathrm{D}_{\mathrm{SA}}$ showed that $\mathrm{EU}$ and $\mathrm{KC}$ were closest to HL (Table 2). The NAD5 intron3 sequences of EU and KC cultivars were identical to those of most wild $A$. koreana (Table 3). Only four wild individuals (three from Mt. Sinbulsan and one from Mt. Sokrisan) revealed a different mitochondrial haplotype, suggesting that the maternal lineages of EU and KC cultivars are identical to those of most wild A. koreana, and separated from the unique lineages of Mt. Sinbulsan (SB) and Mt. Sokrisan (SR) on the Korean peninsula.

Interestingly, we found four haplotypes of the chloroplast trnL-F intergenic spacer region of the obtained sequences (Table 
Table 3. Sequence variations in mitochondrial genotypes of the NAD5 intron3 region identified from korean fir in the present study.

\begin{tabular}{|c|c|c|c|c|c|c|}
\hline & & \multicolumn{5}{|c|}{ Variable site position } \\
\hline & & & 1 & 1 & 1 & 2 \\
\hline & & 1 & 6 & 9 & 9 & 1 \\
\hline Groups $^{\mathrm{z}}$ & Samples $^{\mathrm{y}}$ & 9 & 8 & 7 & 9 & 5 \\
\hline $\mathrm{KC}^{\mathrm{x}}$ & DL (7), GS (5), NM (3), KI (8), JA (3) & & & & & \\
\hline \multirow[t]{2}{*}{ Wild $^{\mathrm{w}}$} & BK (1), DY (3), GY (4), HL (3), JR (4), SR (1) & & & & & \\
\hline & SB (3), SR (1) & $\mathrm{T}$ & $\mathrm{C}$ & $\mathrm{T}$ & G & G \\
\hline
\end{tabular}

${ }_{\mathrm{z}}^{\mathrm{EU}}=$ cultivars in the United States and United Kingdom; $\mathrm{KC}=$ cultivated in South Korea.

${ }^{\mathrm{y}}$ Cultivar names of EU groups and the number of individuals in the $\mathrm{KC}$ and wild populations are shown in the parentheses for each haplotype.

${ }^{\mathrm{x}}$ Codes for cultivated plants in South Korea. DL = Daelim Nursery, Gacheon, South Korea; GS = Gasan Farm, Seoul, South Korea; JA = Jungang Nursery, Seongnam, South Korea; KI = Kangil Farms, Okchoen, South Korea; NM = Namuin Nursey, Uiwang, South Korea.

${ }^{\mathrm{w}}$ Codes for wild populations. BK = Mt. Baekwoonsan; DY = Mt. Deokyoosan; GY = Mt. Gayasan; HL = Mt. Hallasan; JR = Mt. Jirisan; SB = Mt. Sinbulsan; $\mathrm{SR}=$ Mt. Sokrisan. BK, DY, GY, JR, SB and SR are the wild populations in the Korean peninsula and HL is the southmost wild population in Jejudo Island.

Table 4. Sequence variations in chloroplast haplotypes of the trnF-T region identified from korean fir in the present study.

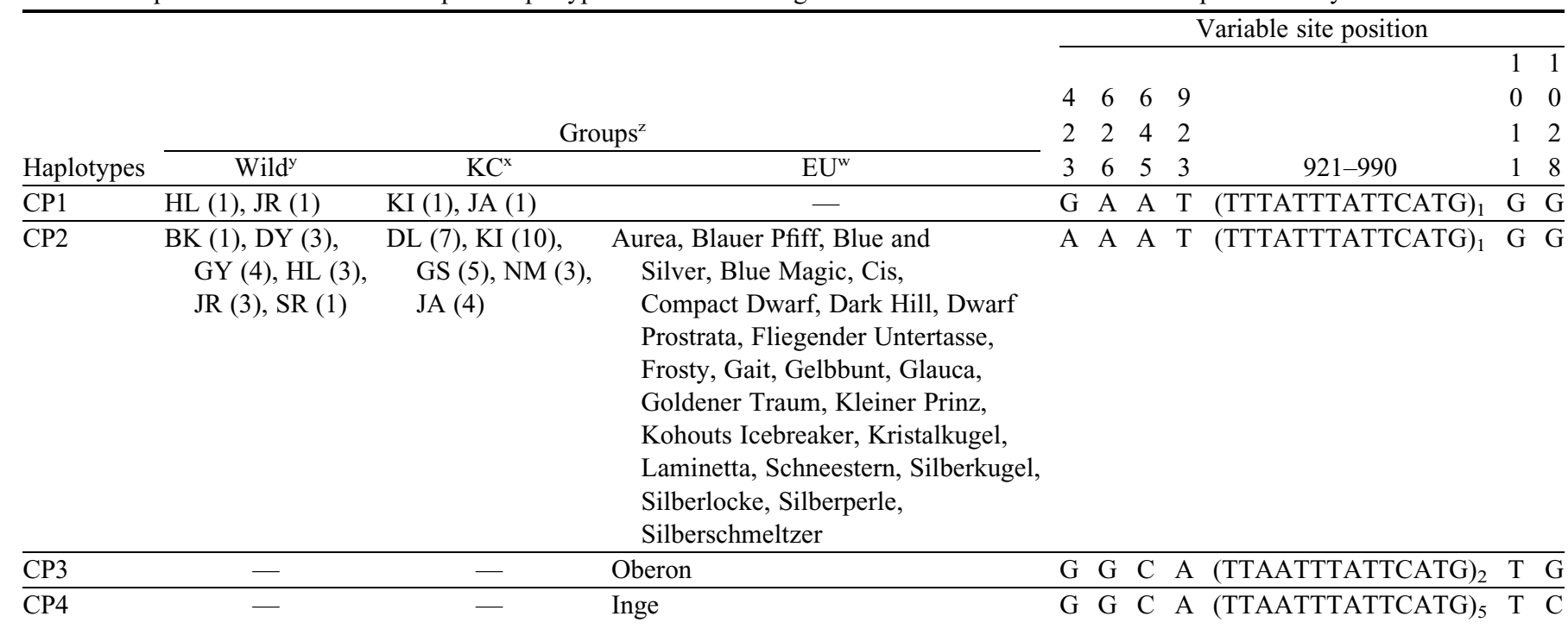

${ }^{\mathrm{z}} \mathrm{EU}=$ cultivated in the United States and United Kingdom; $\mathrm{KC}=$ cultivated in South Korea.

${ }^{\mathrm{y}} \mathrm{BK}=$ Mt. Baekwoonsan; DY = Mt. Deokyoosan; GY = Mt. Gayasan; HL = Mt. Hallasan; JR = Mt. Jirisan; SB = Mt. Sinbulsan; SR = Mt. Sokrisan. BK, DY, GY, JR, SB, and SR are the wild populations in the Korean peninsula and HL is the southmost wild population in Jejudo Island. The numbers in the parentheses indicated the number of individuals analyzed.

${ }^{\mathrm{x}}$ Codes for cultivated plants in South Korea. DL = Daelim Nursery, Gacheon, South Korea; GS = Gasan Farm, Seoul, South Korea; JA = Jungang Nursery, Seongnam, South Korea; KI = Kangil Farms, Okchoen, South Korea; NM = Namuin Nursey, Uiwang, South Korea. The numbers in the parentheses indicated the number of individuals analyzed.

${ }^{\mathrm{w}}$ The cultivar names of EU groups are shown for each haplotype.

4). Together with the sequences downloaded from GenBank, the lineages of those four haplotypes were determined (Fig. 4). The trnL-F sequences from most wild and cultivated individuals were of the CP2 haplotype, which is identical to a previously reported A. koreana sequence (Table 4, Fig. 4). Two wild and two KC cultivated individuals also showed the CP1 haplotype, similar to Abies nephrolepis and Abies veitchii, which are closely related to A. koreana. Interestingly, however, 'Oberon' and 'Inge' were determined to have the CP3 and CP4 haplotypes, respectively, and were clustered with A. balsamea. CP3 and CP4 differed only in the number of iterations of a 14 base pair repeat sequence; two and five iterations, respectively. Hybridization of A. koreana with $A$. nephrolepis has been suggested in wild populations (Chang et al., 1997) and hybridization with $A$. veitchii may be plausible, because those species distribute closely in northeastern Asia. Because A. balsamea is a North American species, however, paternal gene flow from $A$. balsamea to $A$. koreana could occur during cultivation or cultivar development.

To investigate the genetic characteristics of the traded cultivars and to compare them with those of wild populations, 


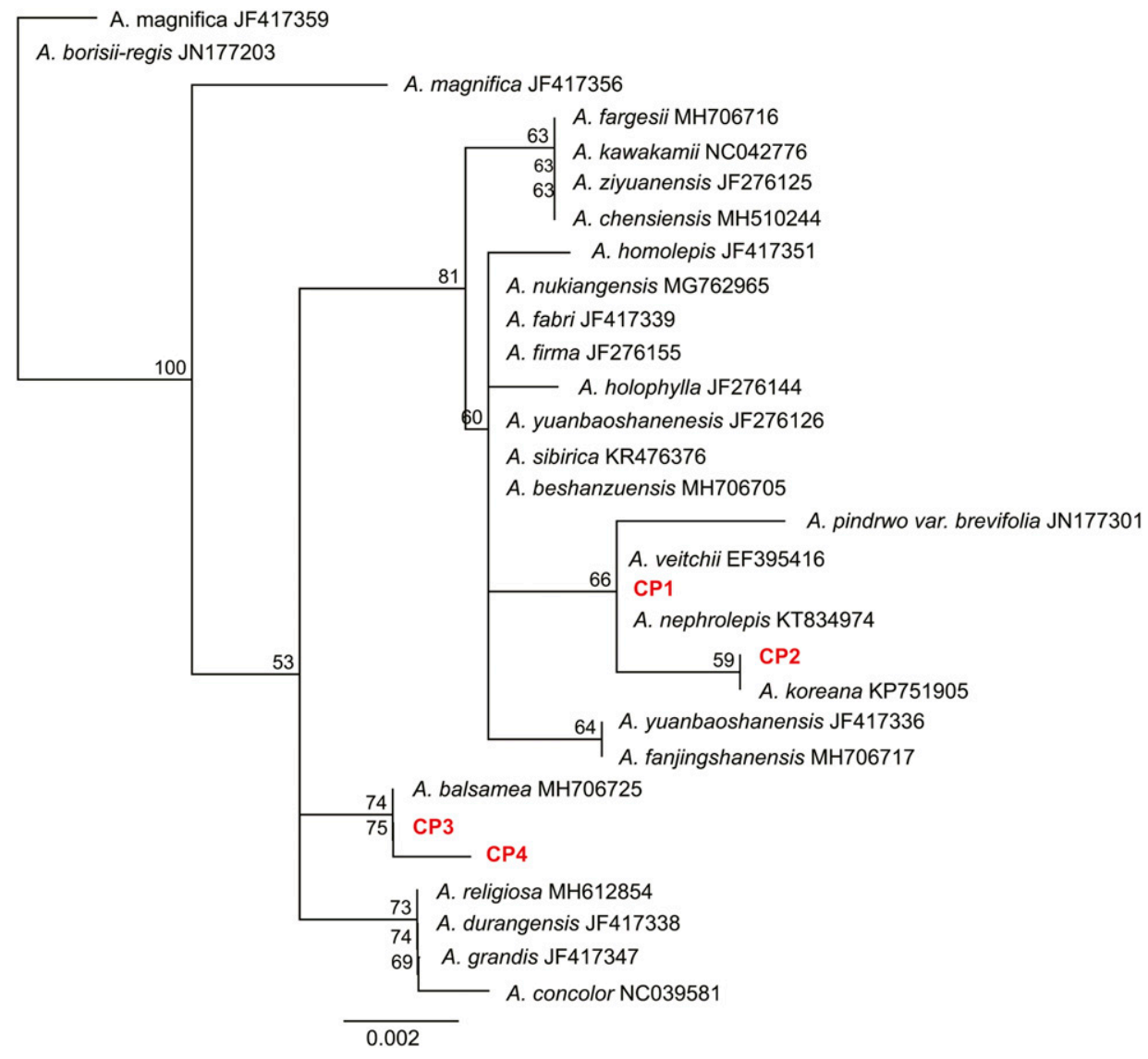

Fig. 4. Neighbor-joining tree of Tamura-Nei distance based on the chloroplast sequences of the trnL-trnF intergenic spacer region of Abies species. Red letters indicate the haplotypes found in the present study. Bootstrap values $>50 \%$ are given above the nodes. The GenBank accession numbers of the sequences analyzed were shown with each species name.

Table 5. Genetic diversity indices of cultivated korean fir based on 19 microsatellite markers.

\begin{tabular}{lcccccccc}
\hline & $\mathrm{N}^{\mathrm{z}}$ & $\mathrm{N}_{\mathrm{a}}$ & $\mathrm{N}_{\mathrm{e}}$ & $\mathrm{R}_{\mathrm{s}}$ & $\mathrm{I}$ & $\mathrm{H}_{\mathrm{o}}$ & $\mathrm{H}_{\mathrm{e}}$ & $\mathrm{F}_{\mathrm{IS}}$ \\
\hline European and American cultivars (EU) & 27 & 7.842 & 4.530 & 6.030 & 1.579 & 0.424 & 0.709 & 0.411 \\
Korean cultivated seedlings (KC) & 36 & 7.842 & 4.163 & 5.621 & 1.509 & 0.570 & 0.687 & 0.173 \\
\hline zumber of individuals sampled (N), mean number of different alleles per locus $\left(\mathrm{N}_{\mathrm{a}}\right)$, mean number of effective \\
alleles per locus $\left(\mathrm{N}_{\mathrm{e}}\right)$, allelic richness expected for a sample size of 20 individuals $\left(\mathrm{R}_{\mathrm{s}}\right)$, Shannon information \\
index (I), observed heterozygosity $\left(\mathrm{H}_{\mathrm{o}}\right)$, expected heterozygosity $\left(\mathrm{H}_{\mathrm{e}}\right)$, inbreeding coefficient $\left(\mathrm{F}_{\mathrm{IS}}\right)$.
\end{tabular}

we analyzed the EU and KC groups separately from the wild populations (Table 5). The average number of alleles per locus $\left(\mathrm{N}_{\mathrm{a}}\right)$ was 7.842 in both categories and the average numbers of effective alleles $\left(\mathrm{N}_{\mathrm{e}}\right)$ were 4.530 in the EU group and 4.163 in the $\mathrm{KC}$ group (Table 5). Allelic richness $\left(\mathrm{R}_{\mathrm{s}}\right)$ was 6.030 in the EU group and 5.621 in in the $\mathrm{KC}$ group. The observed heterozygosities $\left(\mathrm{H}_{\mathrm{o}}\right)$ of the EU and $\mathrm{KC}$ groups were 0.424 and 0.570 , respectively, and the expected heterozygosities $\left(\mathrm{H}_{\mathrm{e}}\right)$ were 0.709 and 0.687 , respectively. The $\mathrm{N}_{\mathrm{e}}, \mathrm{R}_{\mathrm{s}}$, Shannon index (I), and $\mathrm{H}_{\mathrm{e}}$ of the EU group were higher than those of the HL group but lower than those of the KP group (Kwak et al., 2017). The KC group showed lower $\mathrm{N}_{\mathrm{e}}, \mathrm{R}_{\mathrm{s}}, \mathrm{I}, \mathrm{H}_{\mathrm{o}}$, and $\mathrm{H}_{\mathrm{e}}$ values than the $\mathrm{HL}$ group but a slightly higher $R_{s}$ value. The higher diversity indices in the EU group might be due to some level of gene flow from other species during cultivation, as seen for the chloroplast haplotype of 'Oberon' and 'Inge' clustered with A. balsamea.

The inbreeding coefficients $\left(F_{\text {IS }}\right)$ were 0.411 and 0.173 for the EU and $\mathrm{KC}$ groups, respectively. The EU group inbreeding coefficient was significantly higher than that of the $\mathrm{KC}$ group and previous reports from wild populations $\left[\mathrm{F}_{\mathrm{IS}}=0.212-0.269\right.$ (Kwak et al., 2017)]. Moreover, the EU group showed the lowest $\mathrm{H}_{\mathrm{o}}$ despite the high $\mathrm{H}_{\mathrm{e}}$ value. Importantly, A. koreana is often propagated by grafting, which is necessary to maintain desirable cultivar lines and facilitate the mass production of individuals with identical genotypes. The high inbreeding coefficients and the low $\mathrm{H}_{\mathrm{o}}$ of the cultivars in the EU group may be because of grafting or inbreeding between closely related genotypes. By contrast, the $\mathrm{KC}$ population likely derived from seeds collected from wild populations for commercial purposes, without artificial selection or breeding; therefore, their genetic characteristics may not differ significantly from those of wild populations.

Founder effects and selection during crop domestication generally lead to a decrease in genetic diversity, change in allele frequencies, increase in LD, and the elimination of rare alleles in derived populations compared with wild populations (Hyten et al., 2006). Population size during the domestication period and the duration of that period can affect the extent of this loss of diversity (Eyre-Walker et al., 1998). In this study, we found no significant reduction in genetic diversity or changes in allele frequency between the cultivated EU samples and the wild Korean samples, 


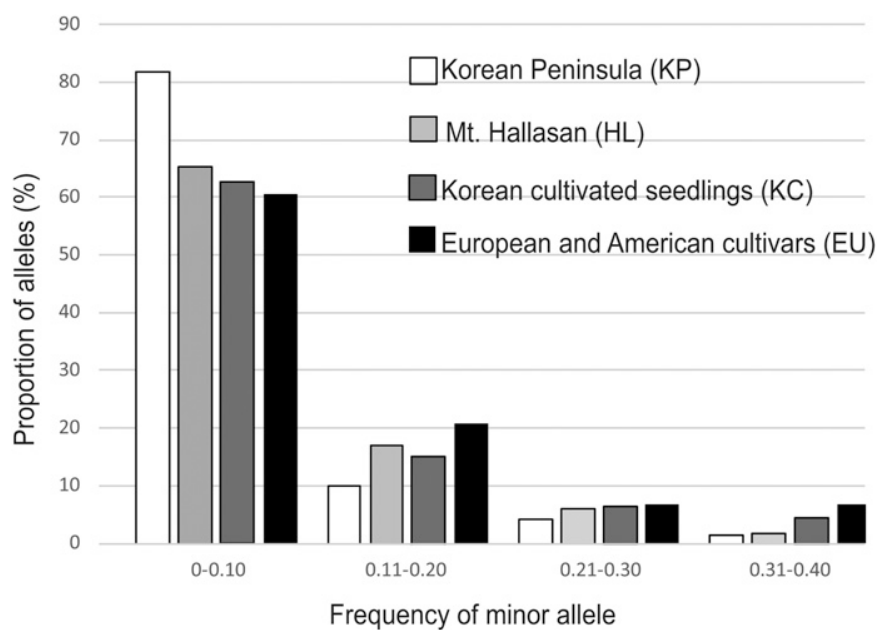

Fig. 5. Distribution of minor allele frequencies within a single population of korean fir on Mt. Hallasan (HL), in other Korean peninsula (KP) groups, and cultivars pooled from Korea (KC) and the United States and United Kingdom (EU).

although a lower proportion of rare alleles and a higher LD were found in the EU group (Fig. 5, Table 6). The apparent lack of an effect of cultivation on genetic diversity is likely explained by a sufficiently large ancestral gene pool, potential gene flow from other species, and variability in trait preferences between growers. In addition, tree breeding is a slow process because of the long generation times (Savolainen and Pyhäjärvi, 2007). A. koreana has been cultivated for a relatively short period, $\approx 100$ years, and has undergone little selective breeding in that time (i.e., likely a few generations). Although asexual propagation (e.g., grafting) could limit the effective population size of plants to a few very popular genotypes, leading to a reduction in genetic diversity (Cornille et al., 2012), we believe that, in this case, grafting helped retain rare alleles without the marked genetic loss that can occur during selection for cultivation. Because genotypes were selected and asexually propagated without generations of breeding, $A$. koreana did not undergo a great reduction in genetic diversity compared with wild populations. Other well-known domesticated crops with long histories of asexual propagation, such as apple (Malus) and grape (Vitis vinifera), revealed similar genetic diversity in their wild progenitors with many old cultivars (Cornille et al., 2012; Myles et al., 2011).

Interestingly, despite the high level of heterozygosity in the EU group, we found that 'Aurea' and 'Compact Dwarf' had identical genotypes for all 19 tested microsatellite loci. 'Kohouts Icebreaker', 'Silberlocke', and 'Silver Show' also had identical genotypes at assessed loci. By contrast, only two of 176 wild individuals from Mt. Gayasan had identical marker genotypes, and two of the KC seedlings were identical. 'Aurea' and 'Compact Dwarf' are popular in nurseries, differing from one another in leaf color and apical dominance (Cregg, 2008). 'Silver Show' is very similar to 'Silberlocke', and both have recurved needles. 'Kohouts Icebreaker' is a miniature form developed from variants of 'Silberlocke'. All of these German cultivars are characterized by an overall white appearance due to their silvery, upward-curved leaf undersides (Auders and Spicer, 2012). Cultivars with identical marker genotypes but different morphological characteristics may arise when small polymorphisms in a single gene result in marked phenotypic changes. For example, a single somatic mutation in Pinus
Table 6. Number of microsatellite marker pairs in linkage disequilibrium (LD) in each population of korean fir.

\begin{tabular}{lc}
\hline Population & LD pairs (no.) \\
\hline Wild & \\
Korean peninsula (KP) & 98 \\
$\quad$ Mt. Deokyoosan (DY) & 32 \\
$\quad$ Mt. Jirisan (JR) & 68 \\
$\quad$ Mt. Gayasan (GY) & \\
Jejudo Island (HL) & 28 \\
$\quad$ Mt. Hallasan (HL) & \\
Cultivated & 258 \\
European and American cultivars (EU) & 54 \\
$\quad$ Korean cultivated seedlings (KC) &
\end{tabular}

$\overline{\mathrm{DY}}, \mathrm{GY}$, and JR are the wild populations in the Korean Peninsula and $\mathrm{HL}$ is the southmost wild population in Jejudo Island.

sibirica causes nonpathological witches' broom (Grasso, 1969; Duffield and Wheat, 1963; Zhuk et al., 2015); however, it may be challenging to use molecular markers to differentiate two closely related cultivars maintained by grafting that have been strongly selected for certain favorable traits, because they may differ only in the few genes responsible for those favorable traits.

Last, taking note that most of the traded cultivars in the United States and United Kingdom originated from Mt. Hallasan, which is home to the southernmost $A$. koreana population, the greater genetic variability in the KP populations [Fig. 2 (shown in green), Table 2) could be a valuable source of horticultural traits or cold-resistance genes.

\section{Literature Cited}

Auders, A.G. and D.P. Spicer. 2012. Encyclopedia of conifers: A comprehensive guide to cultivars and species. Kingsblue Publ., Nicosia, Cyprus. Bretting, P.K. and M.P. Widrlechner. 1995. Genetic markers and horticultural germplasm management. HortScience 30:1349-1356.

Chakraborty, R. and L. Jin. 1993. A unified approach to study hypervariable polymorphisms: Statistical considerations of determining relatedness and population distances, p. 153-175. In: S. Pena, A. Jeffreys, J. Epplen, and R. Chakraborty (eds.). DNA fingerprinting, current state of the science. Birkhauser, Basel, Switzerland.

Chang, C.S., J.I. Jeon, and J.H. Hyun. 1997. An analysis of morphological variation in Abies koreana Wilson and A. nephrolepis (Traut.) Maxim. of Korea (Pinaceae) and their phylogenetic problems. J. Korean For. Soc. 86:378-390.

Cornille, A., P. Gladieux, M.J.M. Smulders, I. Roldán-Ruiz, F. Laurens, B. Le Cam, A. Nersesyan, J. Clavel, M. Olonova, L. Feugey, I. Gabrielyan, X.-G. Zhang, M.I. Tenaillon, and T. Giraud. 2012. New insight into the history of domesticated apple: Secondary contribution of the European wild apple to the genome of cultivated varieties. PLoS Genet. 8:e1002703.

Cregg, B. 2008. Christmas tree species profile: Korean fir Abies koreana. Great Lake Christmas Tree J. 3(2):3-8.

Decroocq, S., A. Cornille, D. Tricon, S. Babayeva, A. Chague, J.P. Eyquard, R. Karychev, S. Dolgikh, T. Kostritsyna, S. Liu, W. Liu, W. Geng, K. Liao, B.M. Asma, Z. Akparov, and T. Giraud. 2016. New insights into the history of domesticated and wild apricots and its contribution to Plum pox virus resistance. Mol. Ecol. 25:47124729 .

Dempewolf, H., G. Baute, J. Anderson, B. Kilian, C. Smith, and L. Guarino. 2017. Past and future use of wild relatives in crop breeding. Crop Sci. 57:1-13.

Duffield, J. and J. Wheat. 1963. Dwarf seedlings from broomed douglas fir. Silvae Genet. 12:129-133. 
Earl, D. and B. von Holdt. 2012. STRUCTURE HARVESTER: A website and program for visualizing STRUCTURE output and implementing the Evanno method. Conserv. Genet. 4:359-361.

Evanno, G., S. Regnaut, and J. Goudet. 2005. Detecting the number of clusters of individuals using the software STRUCTURE: A simulation study. Mol. Ecol. 14:2611-2620.

Excoffier, L., G. Laval, and S. Schneider. 2005. Arlequin ver. 3.0: An integrated software package for population genetics data analysis. Evol. Bioinform. Online 1:47-50.

Excoffier, L. and M. Slatkin. 1998. Incorporating genotypes of relatives into a test of linkage disequilibrium. Am. J. Hum. Genet. 62:171-180.

Eyre-Walker, A., R.L. Gaut, H. Hilton, D.L. Feldman, and B.S. Gaut. 1998. Investigation of the bottleneck leading to the domestication of maize. Proc. Natl. Acad. Sci. USA 95:4441-4446.

Grasso, V. 1969. Dwarf seedlings from witches' brooms of Pinus halepensis. Ital. For. Mont. 24:241-245.

Hyten, D.L., Q. Song, Y. Zhu, I.-Y. Choi, R.L. Nelson, J.M. Costa, J.E. Specht, R.C. Shoemaker, and P.B. Cregan. 2006. Impact of genetic bottlenecks on soybean genome diversity. Proc. Natl. Acad. Sci. USA 103:16666-16671.

Jakobsson, M. and N.A. Rosenberg. 2007. CLUMPP: A cluster matching and permutation program for dealing with label switching and multimodality in analysis of population structure. Bioinformatics 23:1801-1806.

Kim, C.-S., S.-W. Lee, and J.-G. Koh. 2007. Korean fir in Mt. Halla. Jeju Publ., Jeju, Republic of Korea.

Kim, M.S., S.J. Brunsfeld, G.I. McDonald, and N.B. Klopfenstein. 2003. Effect of white pine bluster rust (Cronartium ribicola) and rustresistance breeding on genetic variation in western white pine (Pinus monticola). Theor. Appl. Genet. 106:1004-1010.

Kwak, M., J.K. Hong, J.H. Park, B.Y. Lee, M.H. Suh, and C.S. Kim. 2017. Genetic assessment of Abies koreana (Pinaceae), the endangered korean fir, and conservation implications. Conserv. Genet. 18:1165-1176.

Liepelt, S., R. Bialozyt, and B. Ziegenhagen. 2002. Wind-dispersed pollen mediates postglacial gene flow among refugia. Proc. Natl. Acad. Sci. USA 99:14590-14594.

Liu, K. and S.V. Muse. 2005. PowerMarker: An integrated analysis environment for genetic marker analysis. Bioinformatics 21:2128-2129.
Migicovsky, Z. and S. Myles. 2017. Exploiting wild relatives for genomics-assisted breeding of perennial crops. Front. Plant Sci. 8:460. Mohammadi, S.A. and B.M. Prasanna. 2003. Analysis of genetic diversity in crop plants - Salient statistical tools and considerations. Crop Sci. 43:1235-1248.

Moran, G.F. and J.C. Bell. 1987. The origin and genetic diversity of Pinus radiaita in Australia. Theor. Appl. Genet. 73:616-622.

Myles, S., A.R. Boyko, C.L. Owens, P.J. Brown, F. Grassi, M.K. Aradhya, B. Prins, A. Reynolds, J.-M. Chia, D. Ware, C.D. Bustamante, and E.S. Buckler. 2011. Genetic structure and domestication history of the grape. Proc. Natl. Acad. Sci. USA 108:35303535 .

Neale, D.B. and R.R. Sederoff. 1989. Paternal inheritance of chloroplast DNA and maternal inheritance of mitochondrial DNA in loblolly pine. Theor. Appl. Genet. 77:212-216.

Peakall, R.O.D. and P.E. Smouse. 2006. GenAlEx 6: Genetic analysis in Excel. Population genetic software for teaching and research. Mol. Ecol. Notes 6:288-295.

Pritchard, J.K., M. Stephens, and P. Donnelly. 2000. Inference of population structure using multilocus genotype data. Genetics 155:945-959.

Rosenberg, N.A. 2004. DISTRUCT: A program for the graphical display of population structure. Mol. Ecol. Notes 4:137-138.

Savolainen, O. and T. Pyhäjärvi. 2007. Genomic diversity in forest trees. Curr. Opin. Plant Biol. 10:162-167.

Szpiech, Z.A., M. Jakobsson, and N.A. Rosenberg. 2008. ADZE: A rarefaction approach for counting alleles private to combinations of populations. Bioinformatics 24:2498-2504.

Taberlet, P., L. Gielly, G. Pautou, and J. Bouvet. 1991. Universal primers for amplification of three non-coding regions of chloroplast DNA. Plant Mol. Biol. 17:1105-1109.

Thompson, J.D., D.G. Higgins, and T.J. Gibson. 1994. CLUSTAL W: Improving the sensitivity of progressive multiple sequence alignment through sequence weighting, position-specific gap penalties and weight matrix choice. Nucleic Acids Res. 22:4673-4680.

Wilson, E.H. 1920. Four new conifers from Korea. J. Arnold Arbor. 1:186-190.

Zhuk, E., G. Vasilyeva, and S. Goroshkevich. 2015. Witches' broom and normal crown clones from the same trees of Pinus sibirica: A comparative morphological study. Trees (Berl.) 29:1079-1090. 